\title{
CRM and Mobile Applications:An Overview of Mobile CRM Adoption
}

\author{
Rasha Mohammed Alolayan* \\ Information System Department College of Computer and Information Sciences KSA (2020) \\ Asyah Muzahim Al-Kaabi \\ Information System Department College of Computer and Information Sciences KSA (2020)
}

\begin{abstract}
Purpose - The purpose of this paper is to summarize articles on mobile apps and mCRM to identify important factors affecting their adoption. Research limitations/implications - The relatively small sample size limits the generalization of the results.

Keywords - mCRM adoption, Mobile technology, Technology Acceptance Model, CRM system, B2B sales, Employee satisfaction, mCRM, Personal performance, System use, E-satisfaction, E-loyalty, Mobile banking, Etrust, Mobile marketing, Technology implementation.
\end{abstract}

DOI: $10.7176 / \mathrm{IKM} / 10-2-06$

Publication date: February $29^{\text {th }} 2020$

\section{Introduction}

As consumers move away from traditional media consumption, businesses have to change their approaches to communicating and customer relationships. Mobile apps have taken over, and consumers spend hours on popular social networking sites and video games apps. According to Krishnan \& How (2016), mobile apps are software for general productivity and information retrieval, including emails, calendar, and weather information among other services. The massive surge in mobile app demand led to widespread development for more apps; there are apps for fulfilling almost any function. There are social networking apps, finance, lifestyle, and entertainment apps. User-friendly and effectively developed apps have the potential to improve attract users. Businesses are now adopting mobile customer relationship (mCRM) with the purpose of improving customer relations. mCRM is designed to be executed, operated and accessed through mobile platforms.

\section{Definitions}

A.CRM

Customer relationship management (CRM) it refers to practices, strategies, and technologies that companies use to manage and analyze customer interactions and data throughout the customer lifecycle, with the goal of enhancing customer service relationships and helping in customer retention and driving sales growth.

\section{B.Mobile Application}

A mobile application is a type of application software designed to run on a mobile device, such as a Smartphone or tablet computer. Mobile applications provide users with many services to those accessed on PCs. Apps are generally small, individual software units with limited function.

\section{C.mCRM}

$\mathrm{m}$-CRM has been defined as a communication, either one-way or interactive, which is related to various business line such as sales, marketing, and customer service activities conducted through the mobile medium for the purpose of building and maintaining customer relationship between a company and its customer.

\section{Literature review of mCRM}

Mobile apps are becoming more popular than desktop applications. Mobile apps are user-friendly, they can be downloaded to mobile devices, and they offer flexibility. The average Smartphone user spends $82 \%$ on mobile apps, and the remaining time between calling, texting and e-mailing (Krishnan\& How, 2016). Google Play Store and Apple Store host hundreds of thousands of mobile apps. App manufacturers use the basic free trial version to attract customers, but they have fixed monthly subscriptions and premium versions. Users use their free trial experience to determine whether to pay for the app or not. Manufacturers take into consideration factors that contribute to user intention to purchase apps during development.

Krishnan \& How (2016) examine the app users' purchasing intention using the theory of reasoned action. According to the study, purchasing intention is determined by the perceived usefulness and perceived ease as well as user predisposition and social influence. Theory of reasoned action is concerned with factors that influence behavior. Reasoned action predicts behavioral intention as per an individual an individual situation. Reasoned action considers factors that can limit or affect purchasing behavior. Most mobile apps are free, or their basic free model offer sufficient services such that users do not have to pay for premium subscriptions. The 
app design and promotion affect the user intention to download the app (Krishnan\& How, 2016). Additionally, attitude and subjective norms of mobile app users are essential based on the user history with the app and social influence. The findings of the study are supported by Mukerjee \& Prasad (2017). According to Mukerjee \& Prasas (2017), IT consultants play an essential role in the adoption of mCRM solutions. When the IT department has adequate resources to create the right mCRM solution, they will focus on building a user-friendly technology that will satisfy customers.

Alnawas \& Aburub (2017) adds to the findings of Krishnan \& How (2016). Alnawas \& Aburub (2017) extend the uses and gratification model in understanding the effects of mobile apps on consumer satisfaction. According to the study, many researchers used technology adoption model (TAM) and theory of reasoned action to explore factors influencing adoption and purchasing decisions, and they fail to examine how the effects of the app on satisfaction affect consumer intention to purchase. "Uses and Gratification" approach (U \&G) states that customers' interaction with the surrounding media is a source of value as they provide a number of benefits that can influence user decision to purchase the app or not. Developers of mobile apps have a problem in retaining users/ customers, but the problem can be solved when customers experience the benefits of the app first-hand before they can purchase the app. The study by Alnawas \& Aburub had three objectives, and the first objective was to examine the benefits consumers gained from mobile apps. The second objective was testing the effects of the benefits on customer satisfaction and purchase intention. Lastly, the study aimed at confirming the relationships between consumer satisfaction and purchase intention.

Alnawas \& Aburub (2017) concluded that to understand customer interaction with mobile apps, manufacturers need to shift focus away from the characteristics and features of the app to the customer experiences with the app. The U\&G approach provides a framework for user adoption. Users have primary motives and look for specific types of gratification when downloading mobile apps. When the mobile apps fail to meet user gratification, the user will probably uninstall or stop using the app. The study concludes that app manufacturers should focus on the interaction between users and apps. Manufacturers should create smart and up-to-date apps that stimulate, lighten the mood, hold attention, promote user values, and enhance their decision making. The predictors are influenced by perceived usefulness, perceived enjoyment, and social ties.

On the other hand, a study by Hsiao et al. (2015) investigates the fast adoption of social, mobile Apps such as WhatsApp and WeChat. Social apps have changed the way in which we communicate because they come with superior capabilities that improve one-on-one communication. The researchers focus on how social apps such as WhatsApp continue to retain customers so that businesses can benefit from how to develop user continuance. The study proposed a research framework for social App continuance intention using a postacceptance model of information system (IS). The two predictors of continuance intention are satisfaction and habit. The study concludes that continuance intention of social apps lies on user satisfaction and regular usage. User satisfaction is derived from three factors; utilitarian, hedonic, and social factors. Utilitarian considerations are concerned with the usefulness of the app, while hedonic factors bring enjoyment. Social factors matter as users are more likely to use an app when others are using it.

The study by Hsiao et al. (2015) failed to demonstrate the importance of perceived usefulness as a critical factor in the consumer's decision to continue using a social app. Many useful social apps do not have users probably because users prefer others over them. According to Hsiao, perceived enjoyment is a strong determining factor. App designers should put more effort to emphasize the hedonic value by appealing to consumers' hedonic experiences through a visual attraction.

As mobile apps become common for business and social activities, organizations are adopting them too. A study by Liljander \& Forsberg (2007) was conducted a decade ago when the adoption of mobile technology was on the rise. The researchers wanted to find out how sophisticated mobile technology can offer new services to consumers including customer relationship management (CRM) programs. Mobile technologies are additions to the traditional CRM. The researchers wanted to find out if customers for an airline would be receptive to mobile technology being added to the company loyalty program. The study concluded that customers were not yet fully ready to embrace mobile applications even with the potential of mobile applications improving services in the airline (Liljander \& Forsberg, 2007). Customers with experience with sophisticated mobile services such as the internet had more positive attitudes in comparison to customers with no experience. The success of the mobile applications in CRM is linked with customer readiness to use mobile services.

Ghaleno et al. (2016) posit that mobile marketing influences awareness and brand equity. Brand equity is a multidimensional concept including brand awareness, brand association, brand loyalty, and perceived quality. Brand equity is a source of competitive advantage. The study concluded that mobile marketing or communication through mobile apps have positive effects on brand equity. Ghaleno et al. (2016) cite a study conducted in 2009 by Tsirulnik (2009) which found out that an average of $41 \%$ of individuals receiving messages containing brand name or logo was likely to remember the brand up to the next three months. Communication through texts messages, social networks or online advertisements has positive effects on brand equity, and this influences buyer decision. A study by Choudhury \& Harrigan (2014) builds on previous CRM 
models to identify the benefits of combining modern technology and CRM. Modern technology focuses on interactive communication with customers. Modern CRM generates rich customer information through social media and other mobile apps.

Tileaga et al. (2014) adds that organizations cannot afford to ignore social media. Social media channels such as Twitter and Facebook are necessities for modern businesses, and businesses that need to stay current and competitive have to adopt them sooner. The potential of growing an organization using social media is high. Social media usage is high with the average consumer spending four hours a day on various social media platforms. Consumers use social media for personal and official purposes; thus organizations should encourage employees to use social media to reach out to customers. When employees post products or company information online, their friends and other social media users get to learn about the company.

A decade later after the Liljander \& Forsberg (2007) study, companies and consumers are used to mobile technologies such that mobile customer relationship management (mCRM) is a business concept. In the study by Awasthi \& Sangle (2012) the authors explore how mobile services improve service delivery in the banking sector as well as customer relationship. Mobile banking improves service delivery in comparison to traditional banking as consumers can access their money and banking services at the comfort of their homes. In 2009 more than $91 \%$ of Americans were yet to try mobile banking services necessitating the need for mCRM to help customers understand the services offered by mobile banking and new services under development by the bank. Mobile customer relationship management (mCRM) applications are collaboration technologies that enable organizations to take advantage of different forms of digital platforms. Even before the adoption of mCRM, the adoption of traditional CRM was quite low as it was below 49\%: Thus, the need for a conceptual model exploring the drivers for mCRM use and how mCRM influences organizational outcomes.

As the adoption of mobile applications increases, Berraies et al. (2016) review the effects of mobile banking apps among baby boomers, generation X, and generation Y. The researchers conducted a survey of 361 Tunisian customers across different age groups. The study concludes that quality, price, and emotional perceived values' dimensions of mobile banking are predictors of customers' trust. When customers trust mobile banking, they are more likely to be satisfied and will remain loyal. The study also investigated the difference in mobile banking adoption among different generations. Baby boomers talked about the monetary and quality values to assess the trust towards mobile banking. Baby boomers seek functional aspects in mobile services. Generations $\mathrm{X}$ and $\mathrm{Y}$ are interested in the monetary aspect of the experience, particularly the ease of accessing their money. The different generations talked about the benefits of mobile banking, including the fast transfer of money and transaction security.

The article by Rodriquez \& Trainor (2016) explores the implementation of mobile customer relationship management in the sales department. Organizations struggle with sales force technology implementation due to low adoption. The objective of the article is to develop a model for mCRM antecedents and outcomes by incorporating $\mathrm{mCRM}$ characteristics. The $\mathrm{mCRM}$ conceptual framework details the individual and organizational factors affecting its adoption. Adoption of MCRM is influenced by individual salesperson's capabilities, the perception of the application and social factors. Organizational factors include sales process capability and implementation effectiveness. Salespeople with high levels of computer and technical skills have favorable perceptions of mCRM, and they are likely to adopt technology and encourage their clients to use them too (Rodriquez \& Trainor, 2016). Salespeople with technology skills are highly adaptive, they utilize the tools and resources at their disposal, including mCRM to understand customer needs and improve sales approaches. The salespeople perceptions of ease-of-use and expected usefulness of the technology also affects the adoption of mCRM. Social influence also plays a role in adoption, when a salesperson perceives that other salespeople or supervisors view the mCRM to be useful, the salesperson is more likely to adopt the technology.

The outcomes of mCRM adoption increase collaboration and productivity. CRM improves collaboration between sales department and other departments, particularly marketing, management, and pre-sales support. mCRM enables salespeople to disseminate customer information in real time. Sales technology including mCRM allows professionals to be more productive because they can access critical information from their mobile devices that affect their work. Siadat \& Shafahi (2017) add that mCRM has the potential to promote profitability, increase customer satisfaction and reduce costs. Siadat \& Shafahi uses the SERVQUAL model to measure the service quality of $\mathrm{mCRM}$ for banking corporations in Iran. SERVQUAL measures the existing gap between customer requests and the services they received. The results indicate that banks should improve the quality of their services by taking into consideration customer opinions. MCRM is not just a tool for enhancing customer-organization interaction, but it is used to convey customer complaints, requests, and suggestions that should be used to improve products/services.

A study by Negahban et al. (2016) adds to the findings of Rodriquez \& Trainor (2016). According to Negahban et al. (2016), MCRM enables organizations to increase their business performance through the delivery of better products and services to customers. Businesses now can offer personalized services and enhance quality dimensions in different departments. The researchers concluded after conducting extensive 
research on implementation of $\mathrm{mCRM}$ in organizations in South Korea. The study aimed at finding out the aspects influencing the successful implementation of mCRM. The findings of the study state that IT infrastructure, local business support including technical resources and mCRM knowledge, and human resource capabilities. IT infrastructure is used to maintain quality customer data while allowing easy availability and accessibility of customer data. The technical expertise of the IT team, as well as education and support for the mCRM users, will determine whether mCRM will be adopted successfully or not. Negahban et al. (2016) tested human resource capabilities associated with MCRM, and they found out that a high degree of MCRM knowledge leads to higher mCRM system service quality. Appropriate and effective training programs encourage $\mathrm{mCRM}$ adoption within the organization.

mCRM has been praised for the positive contribution to brand equity, productivity, and performance. However, there is a need to examine the employee's personal performance after the adoption of mCRM. The article by Kim et al. (2015) explores employee personal experiences with mCRM. Employees reported that they would use mCRM if it is appropriately designed to enhance customer satisfaction. The researchers examined mCRM characteristics that encourage utilization among employees. The characteristics include system quality, information quality, and service quality. Personal performance is mediated by system use and user satisfaction. mCRM quality, mediating factors of user satisfaction and system use are associated with better individual performance and frequency of system use. Employees are more likely to utilize mCRM when it can seamlessly connect with other applications.

Organizational leadership should be at the forefront of encouraging adoption of mCRM. Karjaluoto et al. (2018) analyze the behavioral intentions of business-to-business (B2B) sales manages to use CRM systems in their day to day activities. The study uses the technology acceptance model (TAM) as the theoretical foundation for the research study involving 105 international sales managers. The study findings indicate that managers are likely to use the mobile CRM system on the basis of perceived innovativeness, perceived risk, and perceived reachability. Managers are more likely to utilize mCRM when they feel that it is innovative, and it carries fewer risks.

\section{4 limitations and objectives}

The literature review is a summary of studies on CRM and mobile applications. Some of the studies present models for mCRM adoption, while others focus on the effects of mobile apps in modern businesses. The studies have notable limitations worth exploring. The first limitation lies in the data collection method. Most researchers used a small number of participants in their studies; thus, the results cannot be generalized. Some studies were geographically limited to one country, for example, the study Awasthi \& Sangle (2012) was geographically limited to banks in India. Other studies had the same problem because they were geographically limited too. Limiting the studies to a particular area implies that the participants are affected by unique social and cultural factors. Most studies also used relatively small sample sizes. Another limitation is that researchers failed to consider all the variables that would lead to a better understanding of the research question. Also, there is no study had a comparison study of mCRM tools to highlight which one is better for implementation.

Despite the limitations of generalizability and small samples, the studies examined how businesses can take advantage of mobile applications and CRM. The studies provided the theoretical foundation for mobile app and mCRM adoption. The studies also explored different factors influencing the adoption and usage of mCRM. There are individual and organizational factors that influence adoption of mCRM. The organization should dedicate resources and support to MCRM influence its adoption. Understanding the benefits of well implementing MCRM will have a positive effect on organizational performance.

Our Objective is to put all this information together after studying mCRM adoption in one of the companies in Riyadh to recognize the importance of adopting mCRM in today's businesses.

\section{Methodology}

Research methodology consisted of collecting information from previous research and link it with a real-life case study on one of the existing companies in Riyadh.

In order to have a clear image of adopting mobile CRM in business, an interview was done on $25^{\text {th }}$ of November 2018 by Adaptive TechSoft which represents one of the technical institutions in Riyadh to highlight the effect of adopting m-CRM on the company.

First, the interviewer had to ask some questions to have a good background about using mCRM in the company which leads him to these points:

- Mobile applications are always used in the company.

- $\quad$ The company prefers using electronic payment rather than a cash payment.

- The company sometimes conducts training and awareness before using phone applications.

- The company never faces resistance from the use of phone applications.

- The company never faces a crisis of its customers by using phone applications to manage its 
relationship with its customers.

- The company continuously updates its applications.

- Mobile applications improve the company's management towards clients.

- Mobile applications sometimes affect performance indicators (profitability).

- The number of customers increased with phone applications.

- While shifting to use mobile CRM applications, a change must occur in the staff.

- There is a strategic change in management plans within the company.

- The company sometimes seeks customers' reaction towards changes.

- The company sometimes works to meet customers' suggestions.

Next, some questions were asked to have an insight view of the subject and the results were as follows:

\section{- The company's tasks:}

ATS's open, standards-based approach enables customers to secure delivery of new and enhanced systems while maximizing on efficiency and cost-effectiveness. All ATS applications are web-enabled and run on a variety of computer systems and platforms; they are integrated Oracle-based solutions, scalable and portable, all of which support international standards.

ATS policy in systems development is based on a thorough and complete market research of customers' current requirements, taking into consideration future needs and expansion plans.

\section{ATS applications include:}

CareWare ${ }^{\circledR}$ This is a Hospital Information Management System, which covers Medical, Financial, Administration, and Material management systems. This product is implemented in various hospitals in Jordan and across the Arab world. The System is fully bilingual, parametric, and modular-based. CareWare ${ }^{\circledR}$ is developed under Oracle using Developer and can run under UNIX, NT and any other platforms that support Oracle.

e-Register ${ }^{\circledR}$ This is a complete web-enabled University Management Information System that facilitates all levels of university decision-makers enabling them to retrieve, access, and process accurate data at the appropriate times. It is an online, integrated system designed to fully automate activities and functionalities typically available in a university environment that follows the credit hour system. e-Register is developed using a state-of-the-art relational database management system (Oracle) utilizing powerful development tools, Developer, Designer, Discoverer, ASP, HTML, JavaScript and Java Applets.

e-SCOOI ${ }^{\circledR}$ This is a web-based School Management Information System built to create infrastructure for a school community, consisting of school management, parents, teachers, and students. The modular-based system facilitates communication and continuous dialogue between members of the educational process in many countries with the purpose of knowledge exchange.

\section{Third party Administration Systems include:}

SafeNet This product manages the relationship between insurance, insured, healthcare providers and patients with the purpose of reducing medical expenses, and is also considered a rich medical resource. The system helps users prevent abuse and frauds of health policies. With various reports provided from the system, decisionmakers are able to determine the best way to handle policies for insured companies and self-insured funds.

- ATS company uses "CERTACURE APP" as an example of its CRM mobile applications

- The company's branches:

Adaptive TechSoft (ATS) is a purpose-built corporation, specializing in the design and implementation of quality software applications essential to a variety of sectors, namely health care and education.

Headquartered in Amman, Jordan, ATS today stands at the forefront of software houses with branches in Saudi Arabia and Yemen, including dealers in the United Arab Emirates and Kuwait. The corporation operates in virtually all Arab countries and has created, in just several years, a proven track record of success, aiming to place ATS in the near future on the New York Stock Exchange.

- The company's evolvement:

ATS has gained a majority share in the Jordanian market, particularly in the health and educational sectors. Two years ago, the corporation entered the regional market specializing in large-scale systems for medium to large-size establishments. ATS has acquired a significant share in Saudi Arabia and the UAE.

- The company uses RCH Hospital (Riyadh Care Hospital) as new projects related to GAL applications in managing the customer relationship.

6 Results

After seeking for information and asking questions about mCRM adoption, we found that there are reasons of 
mCRM adoption that any company should keep it in mind while applying or enhancing their CRM systems. Also, there are factors may influence its adoption that may affect the good implementation of mCRM and it can be organizational or individual reasons. Then, we think that understanding the benefits of applying mCRM will lead the organizations to put more efforts in adopting mCRM applications. Finally, a conceptual model has been described from previous researches to add dimensions of how to adopt mCRM within organizations followed by mCRM tools

\section{a. reasons of adopting $m C R M$}

- Technological innovation in terms of integrating MB applications becomes necessary for banks that aim to attract customers, especially digital citizens. (Berraies \& Ben Yahia \& Hannachi 2017).

- Sales firms challenged with gaining user adoption in traditional CRM need to integrate mCRM into their sales process. Integration of these technologies may lead to a number of benefits such as improved sales and marketing alignment, access to decision makers, shorter sales cycles, and better collaboration with customers. (Rodriguez \& Trainor 2016).

- Incorporating three key constructs: personal innovativeness in the domain of IT, perceived risk and perceived reachability, alongside the well-known TAM constructs, are important drivers of mobile CRM system adoption among B2B sales managers. (Karjaluoto \& Töllinen \& Pirttiniemi \& Jayawardhena 2014).

- Personal innovativeness in the domain of IT is a strong predictor of intervening variables influencing intention in the mobile CRM system context. Thus, the more innovative the salespeople, the more likely they are to adopt a mobile CRM system. (Karjaluoto \& Töllinen \& Pirttiniemi \& Jayawardhena 2014).

- $\quad$ E-trust is specific to the e-client as his confidence increases, his loyalty will increase.

\section{b. Individual and organizational factors that influence adoption of mcrm}

- Level of IT knowledge among the employees and customers.

- Attitude towards the use of new technologies.

- The quality of data stored in the system.

- The appearance of new technologies.

\section{c. The Benefits of applying mcrm on organizations}

mCRM can overcome existing CRM restrictions where there are no limits to CRM; it can easily access client information anytime, anywhere, through direct interaction with them. And connect with sales resources (i.e. marketing and management) to achieve better performance. This builds long-term relationships with customers because it provides them with e-trust, e-satisfaction, and loyalty, values that the customer search for after using the company's mobile applications, and it provides an effective way to increase collaboration between buyers, sales staff, and internal functional areas.

mCRM B2B companies and mobile CRM systems developers can help understand key factors that can play a role in influencing the intent of adopting a CRM mobile system from the point of view of the sales manager. (Karjaluoto \& Töllinen \& Pirttiniemi \& Jayawardhena 2014).

The use of mCRM allows sales professionals to communicate more effectively with internal stakeholders. This leads to improve productivity, enhance efficiency, and increase the confidence in business relationships.

Employees can also benefit from fast and continuous information updates, engaging in real-time marketing and improved personal performance. Because mobile devices are the core feature of dynamic mobility, Smartphones represent a new paradigm that reflects the mobile revolution of corporate governance. Previous research has shown that adoption of technological innovations is usually risky but appears to be diminishing when users become familiar with the CRM system. (Karjaluoto \& Töllinen \& Pirttiniemi \& Jayawardhena 2014).

The mCRM application can increase the number and amount of information people record. As more information is captured, CRM becomes more useful for salespeople in managing their daily activities. As the sales staff record data, CRM becomes more useful from the analytical/strategic perspective of both sales representatives and sales managers because of the availability of information that can be analyzed. Thus, $\mathrm{mCRM}$ can increase the use of the CRM system by employees and managers across the organization. Ultimately, this increased use is likely to result in many positive results from CRM technology investments, such as increased productivity. (Rodriguez \& Trainor 2016).

Increased number of calls to prospects and increased time uncovering new selling opportunities. By enabling sales professional to have more information at their fingertips through the use of mobile CRM applications, sales professionals spend less time on administrative tasks and more time on selling activities. By tracking these types of sales activities, we can correlate the relationship with the adoption of mCRM. (Rodriguez \& Trainor 2016).

\section{d. Conceptual model}

The CRM adoption of the model shown in Figure 1 is the adoption of mCRM, which is based on traditional client management functions that are introduced in mobile platform applications. Mobile apps support many 
sales functions (e.g. presentations, information, contacts, sales reports, etc.) that provide a great deal of mobility and reach a large number of customers. mCRM utilizes customer-centric technology tools that help sales staff formulate strategies to achieve effectiveness in their sales methods. Develop and manage long-term relationships with customers as well as assist them in managing sales processes and implementing strategic tasks. Figure 1 describes the individual and regulatory effects on mCRM adoption and expected outcomes of adoption. (Rodriguez \& Trainor 2016).

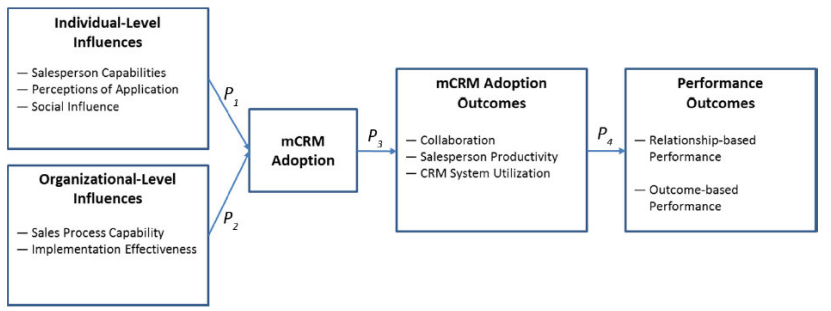

\section{e. mCRM tools}

Fig. 1. Conceptual model

There are many mCRM tools for example: Highrise,Insightly, Zoho CRM, Pipedrive, Capsule,Freshsales,HubSpot,Apptivo and Base.

We have found a comparison between some of these tools in which it is going to be helpful for any company to decide whether it is suitable for implementation according to their IT infrastructure or not.

The comparison indicators are given by answering these questions: Who is the creator of this application? When it is last updated? Does it work with iOS and android tablets? What is the mobile platform? Does it have off line access?

\begin{tabular}{|c|c|c|c|c|c|c|c|}
\hline System & Creator & $\begin{array}{l}\text { Last } \\
\text { Updated }\end{array}$ & $\begin{array}{l}\text { Android Tablet } \\
\text { Application }\end{array}$ & $\begin{array}{l}\text { iOS } \\
\text { Tablet } \\
\text { Application }\end{array}$ & $\begin{array}{l}\text { Mobile } \\
\text { Platform }\end{array}$ & $\begin{array}{l}\text { Offline } \\
\text { Access }\end{array}$ & $\begin{array}{l}\text { Free } \\
\text { Mobile } \\
\text { Access } \\
\end{array}$ \\
\hline Base CRM & Base CRM & 2018 & Yes & Yes & $\begin{array}{l}\text { iOS } \\
\text { Android } \\
\text { Windows } \\
\text { phone }\end{array}$ & Yes & Yes \\
\hline $\begin{array}{l}\text { Elements } \\
\text { CRM }\end{array}$ & $\begin{array}{l}\text { Elements } \\
\text { CRM }\end{array}$ & 2013 & No & Yes & $\mathrm{iOS}$ & NA & Yes \\
\hline $\begin{array}{l}\text { Microsoft } \\
\text { Dynamics }\end{array}$ & Microsoft & 2015 & Yes/Third party & $\begin{array}{l}\text { Yes/Third } \\
\text { party }\end{array}$ & $\begin{array}{l}\text { Windows } \\
\text { phone }\end{array}$ & Yes & Yes \\
\hline Oracle CRM & $\begin{array}{l}\text { Oracle } \\
\text { Cooperation }\end{array}$ & 2013 & Yes & Yes & $\begin{array}{l}\text { iOS } \\
\text { Android }\end{array}$ & Yes & Yes \\
\hline Pipedrive & Pipedrive & 2018 & Yes & Yes & $\begin{array}{l}\mathrm{iOS} \\
\text { Android }\end{array}$ & Yes & Yes \\
\hline Salesforce & Marc Benioff & 2013 & Yes & Yes & $\begin{array}{l}\text { iOS } \\
\text { Android }\end{array}$ & Yes & Yes \\
\hline$S A P C R M$ & SAP & 2013 & Yes & Yes & $\begin{array}{l}\text { iOS } \\
\text { Android }\end{array}$ & Yes & Yes \\
\hline Zoho CRM & $\begin{array}{l}\mathrm{ZOHO} \\
\text { Cooperation }\end{array}$ & 2013 & Yes & Yes & $\begin{array}{l}\text { iOS } \\
\text { Android }\end{array}$ & Yes & No \\
\hline
\end{tabular}

Base CRM appears to be recommended selection to use during the implementation of mCRM in an organization according to the comparison.

\section{future work}

This research aims to better understand how Mobile CRM become one of any business aspects these days. Future research can measure the impact of $\mathrm{mCRM}$ on specific organizational objectives and performance metrics to better interpret the phenomenon of mobile technology. Some studies build the foundations for a more comprehensive research framework to understand and illustrate the use of mCRM technology and its potential to regulate sales. Additional studies can analyze the effect of mCRM on performance through other processes. It would also be useful to conduct a comparative study between two or several countries. In fact, the values of individuals vary from culture to culture and a comparison study of some mCRM mobile applications that can 
lead to the best one in practice is needed for better research results.

\section{Conclusion}

In this study we had an overview of mCRM adoption and try to fill some gaps by collecting previous information from several studies and answering some questions about the importance of applying mCRM in companies to figure out the causes and factors affecting the adoption of mCRM, the benefits of mCRM, some mCRM tools to choose from.

More researches are needed that shows how companies benefit in different industries and how their value is configured with CRM mobile applications. Future researches can rely on business surveys to confirm CRM mobile adoption in many industries. CRM mobile does not only help companies improve their relationship with their customers, but also helps them reduce the cost of acquiring new customers. CRM mobile applications offer opportunities and challenges, but companies need to justify their need to adopt mobile phone applications, as further investigation of trends and current features offered by vendors may help to select the right applications.

\section{References}

[1] Karjaluoto, H., Töllinen, A., Pirttiniemi, J., \& Jayawardhena, C. (2014). Intention to use mobile customer relationship management systems. Industrial Management \& Data Systems, 114(6), 966-978.

[2] Kim, C., Lee, I. S., Wang, T., \& Mirusmonov, M. (2015). Evaluating effects of mobile CRM on employees' performance. Industrial Management \& Data Systems, 115(4), 740-764.

[3] Berraies, S., Ben Yahia, K., \& Hannachi, M. (2017). Identifying the effects of perceived values of mobile banking applications on customers: Comparative study between baby boomers, generation $\mathrm{X}$ and generation Y. International Journal of Bank Marketing, 35(6), 1018- 1038.

[4] Rodriguez, M., \& Trainor, K. (2016). A conceptual model of the drivers and outcomes of mobile CRM application adoption. Journal of Research in Interactive Marketing, 10(1), 67-84.

[5] Alnawas, I., \&Aburub, F. (2016). The effect of benefits generated from interacting with branded mobile apps on consumer satisfaction and purchase intentions. Journal of Retailing and Consumer Services, 31, 313-322.

[6] Hsiao, C. H., Chang, J. J., \& Tang, K. Y. (2016). Exploring the influential factors in continuance usage of mobile social Apps: Satisfaction, habit, and customer value perspectives. Telematics and Informatics, 33(2), 342-355.

[7] Liljander, V., Polsa, P., \& Forsberg, K. (2007). Do mobile CRM services appeal to loyalty program customers? International Journal of E-Business Research (IJEBR), 3(2), 24-40.

[8] Krishnan, K. S. T., \& How, L. K. (2016). The Effect of Mobile Apps on Gen Z's Intention to Download Apps in Malaysia. International Journal of Advanced and Multidisciplinary Social Science, 2(3), 51-60.

[9] Awasthi, P., \&Sangle, P. S. (2012). Adoption of CRM technology in multichannel environment: a review (2006-2010). Business Process Management Journal, 18(3), 445-471.

[10] Choudhury, M. M., \& Harrigan, P. (2014). CRM to social CRM: the integration of new technologies into customer relationship management. Journal of Strategic Marketing, 22(2), 149-176.

[11] Ghaleno, M. R., Zavareh, M. R., \&Bahrami, E. Effect of Mobile Marketing on Customer-oriented Brand Equity in Insurance Industry. International Journal of Management, Accounting and Economics, 3 (3), 185201.

[12] Mukerjee, H. S., \& Prasad, U. D. (2017). Definitions of Project Success in Implementation of Customer Relationship Management (CRM) Information Technology (IT) Solutions: Perspectives of Consultants from India. South Asian Journal of Management, 24(4).

[13]Negahban, A., Kim, D. J., \& Kim, C. (2016). Unleashing the Power of mCRM: Investigating Antecedents of Mobile CRM Values from Managers' Viewpoint. International Journal of Human-Computer Interaction, 32(10), 747-764.

[14] Siadat, S.H. \&Shafahi, S. (2017). Assessing the Quality of Applied Services in Mobile Customer Relationship Management: Case Study of Banking Informatics Corporations in Iran. International Journal of Management, Accounting and Economics, 4 (4), 367-378.

[15] Tileaga, C., Nitu, C. V., \&Nitu, O. (2014). Using the new technologies of social media in the implementation of a customer relationship management system. Studies in Business and Economics, 9(2), $117-128$

[16] Awasthi, P. \& Sangle P.S (2012). The importance of value and context for mobile CRM services in banking. 